\title{
Features of heart rate variability in hockey players aged 15-16 years in sports training
}

\author{
ELENA SURINA-MARYSHEVA ${ }^{1}$, VADIM ERLIKH ${ }^{2}$, LYDMILA KRIVOKHIZHINA $^{3}$, KSENIA \\ MARCHENKO $^{4}$, SALAVAT KANTYUKOV $^{5}$ \\ ${ }^{1,2,4}$ Institute of Sport, Tourism and Service,South Ural State University (National Research University), RUSSIA \\ ${ }^{3,5}$ South Ural State Medical University, RUSSIA
}

Published online: December 31, 2019

(Accepted for publication: December 19, 2019)

DOI:10.7752/jpes.2019.04385

\begin{abstract}
The article aims to identify the features of heart rate variability in elite hockey players aged 15-16 years $(n=36)$ in the annual training cycle. Heart rate variability was studied in the preparatory and competitive preparation periods (July-December-February). The comparison group consisted of students of a college of physical education of a similar age (examination time: February). In the work, standard methods for assessing HRV at rest (time domain and spectral analysis method) were used. The reactivity coefficient of the parasympathetic system (30: 15) in response to orthostasis was calculated. By the middle of the competitive period, VLF waves decrease; HF waves increase from $34 \%$ to $43 \%$ and there is a decrease in VLF waves. The ratio of the power of spectral waves changes from $\mathrm{LF}<\mathrm{HF}<\mathrm{VLF}$ to $\mathrm{LF}<\mathrm{VLF}<\mathrm{HF}$. All changes in HRV indicators are preserved until the end of the competitive period. The value of 30: 15 remains stably low throughout the observation period. Relative to students with high motor activity, hockey players aged 15-16 years have the reduced values of LF (ms2), LF\%, LF / HF 30:15 (hockey players: $\mathrm{M} \pm \mathrm{m}=1.31 \pm 0.04 ; 0.21$; physically active students: $\mathrm{M} \pm$ $\mathrm{m}=1.51 \pm 0.05 ; \mathrm{SD}=0.18(\mathrm{p}<0.001)$; increased $\mathrm{RMSSD}$ and $\mathrm{HF} \%$. In the competitive period in elite hockey players, the vagal effect on the rhythm of the heart increases, which helps to increase the efficiency of the heart at rest. The power of the higher subcortical centers of the autonomic system remains unchanged and corresponds to the age of the sample. The increased power of the higher subcortical structures of the autonomic system on heart rate regulation is due to the features of the pubertal period.In response to orthostasis, heart rate regulation is not yet perfect, which may be a consequence of exposure to irrational physical exertion.

Key Words: heart rate variability, athletes, puberty, hockey
\end{abstract}

\section{Introduction}

Adaptation to physical activity among hockey players aged 15-16 years occurs against the background of an increase in psychogenic factors, including intra-team competition (Pal'ov, R., Pivovarniček, P., Jančoková, L., 2017). The competitive process and increased competition in the team have a significant stressful effect on the body of athletes against the background of ongoing neurohormonal perturbations of the pubertal period. An early sports specialization, which contributes to the development of psychological stress and an increase in the risk of injuries (Jayanthi N., Pinkham C., Dugas L., Patrick B., \& Labella C., 2013), has an adverse effect on the functional status of athletes in the pubertal period. In addition, athlete training often takes place against the background of insufficientrecovery of the body (Iordanskaya F.A., 2010). Hyperfunction of hypothalamic structures and the pituitary gland increased production of stress hormones and androgens, as well as secretory activity of the thyroid gland (Shaikhelislamova M.V., Sitdikov F.G., Dikopolskaya N.P., Bilalova G.A., \&Kayumova G.M., 2009).

Heart rate changesare a universal reaction of the body to any endogenous or exogenous effect, the features of which are used to obtain urgent information about the functional status of the body (Baevsky, R.M., \& Ivanov, G.G.; 2001; Chuyan E.N.,Biryukova E.A., \&RavaevaM.Yu., 2008; Tonello L., Rodrigues F.B., \& Souza J.W., 2014). Heart rate variability (HRV) is a generally accepted method for assessing the mechanisms of regulation of the visceral systems of the human body (Sivokhov V.L., Sivokhova E.L., \&Mirolevich D.V., 2010; Leti T, \&Bricout V.A., 2013). According to some authors, HRV is determined by the influence of environmental factors, including physical exertion (Kudrya O.N., 2009; Karpenko Yu.D., 2010). At the same time, many researchers could not find these relationships (Seifert G., Calaminus G., Wiener A., \&Cysar D., 2014). According to Shlyk N.I. (Shlyk N.I., 2009) HRV is determined by the genetically determined type of autonomic regulation, which is established by 6-8 years and remains unchanged when the strength of environmental factors 
is adequate to the adaptive capabilities of the body. It has been proven that a decrease in heart rate variability precedes hemodynamic, metabolic, and energy disorders and is the earliest prognostic sign of human dysfunction (Baevsky R.M., \& Ivanov G.G., 2001; Mikhaylov V.M., 2000; Ban ' A.S., \&Zagorodnyi G.M., 2010). It is believed that according to HRV parameters, it is possible to assess the adaptive capabilities of athletes and predict the likelihood of overtraining (Shlyk, N.I., 2009; Gavrilova E.A., 2015).

The article aims to identify the features of heart rate variability in elite hockey players aged 15-16 years $(n=36)$ in the annual training cycle.

\section{Materials\&Methods}

The study was performed on the premises of the ice hockey sports school "Tractor" (Russia). Hockey players aged 15-16 years participated in the study (Role: forwards, defenders; $n=36$ ). The total experience in hockey was 9-10 years. The inclusion of players from 15 to 16 years old in one group is determined by the sports training program in performance enhancement groups. A prospective longitudinal study was organized in three stages: July - the beginning of the annual training cycle, December - the middle of the competitive period, February - the end of the competitive period. The comparison group consisted of students of the Chelyabinsk College of Physical Education aged 16 years. The choice of the comparison group was made based on the high level of physical activity of students of the college of physical education (physical education classes - 6 times / week; total duration of classes - 1.5-3 hours). In the comparison group, theexamination was conducted in February.

In accordance with the Declaration of Helsinki, before the study, parents of the hockey players provided their voluntary informed written consent. The study was approved by the ethics committee of the South Ural State University.

The study of HRV was carried out after a day of rest in the morning in a medical laboratory. According to the preliminary examination of the doctor of the school "Tractor", all the athletes were healthy. ECG recording conditions were standardized: 1.5-2.0 hours after a meal; the volume of fluid taken during breakfast was $200-250 \mathrm{ml}$.

Baseline ECG recording was carried out for 5 minutes in the supine position (state of relative physiological rest). In the work, international standards of electrocardiographic studies were observed for assessing HRV in a short ECG record (Heart rate variability. Standards of measurement, physiological interpretation, and clinical use. 1996). Respiratory rhythm can have a significant disturbing effect on HRV indicators, thereby decreasing the reliability of research methods (Gisselman A.S., D'Amico M.S., James M., 2017).Therefore, when there are signs of spontaneous breathing (breath holding, spontaneous expiration and inspiration), non-stationary ECGsignals were monitored and excluded from analysis. ECG was recorded using a VNS-MICRO computer electrocardiograph (Neurosoft, Russia). The equipment used in the experiment is certified according to the international standards. ECG was recorded with reusable clamp electrodes on a limb (Italy, Fiab) in II, III, and aVL leads. When conducting an active orthostatic test (AOT), the ECG was recorded within 1 minute after a change in body position (transition period). Processing of the research results was carried out using the Polyspectrum HRV analysis program (Neurosoft, Russia). If necessary, the arrangement of markers in the QRS complex was manually adjusted.

HRV analysis was carried out using standard methods (Heart rate variability. Standards of measurement, physiological interpretation, and clinical use. 1996; Mikhaylov V.M., 2000). The following indicators of the time domain method were calculated:RMSSD - the square root of the sum of the differences in a sequential series of cardiac intervals SDNN - standard deviation of all R-R intervals. In accordance with the international standard, the methods of spectral analysis were used: TP - the sum of all waves in the spectrum; HF - high-frequency waves $(0.15-0.40 \mathrm{~Hz})$; LF - low-frequency waves $(0.04-0.15 \mathrm{~Hz})$; VLF - very low frequency waves $(\leq 0.04 \mathrm{~Hz})$.

The reactivity of the parasympathetic system was assessed using coefficient 30:15 (30: 15) calculated in the transition period of the active orthostatic test(Mikhaylov V.M., 2000). 30: 15 is defined as the ratio of time (in seconds) of the longest R-R interval ("peak of the cardiorhythmogram") to the time of the shortest R-R interval. According to the literature, 30: 15 has moderate reproducibility of research results over a single day (Kowalewski M.A., \& Urban M., 2004).

\section{Results}

Table 1 shows the results of a statistical analysis of heart rate variability. The total regulation power (SDNN; TP) from the beginning of the annual training cycle to the end of the competitive period at rest remains unchanged. There are no changes in the influences of the vasomotor center (LF) and vagus nuclei (RMSSD and HF $\mathrm{ms}^{2}$ ) on the heart rhythm (Table 1). 


\section{ELENA SURINA-MARYSHEVA, VADIM ERLIKH, LYDMILA KRIVOKHIZHINA, KSENIA MARCHENKO, SALAVAT KANTYUKOV}

Table 1 . Heart rate variability in hockey players $15-16$ years old in the annual training cycle (time domain method). Data are means $( \pm \mathrm{SD})$

\begin{tabular}{|c|c|c|c|c|}
\hline Indicator & $\begin{array}{c}\text { July } \\
\mathrm{M} \pm \mathrm{SD} ; \mathrm{n}=36\end{array}$ & $\begin{array}{c}\text { December } \\
\mathrm{M} \pm \mathrm{SD} ; \mathrm{n}=33\end{array}$ & $\begin{array}{c}\text { February } \\
\mathrm{M} \pm \mathrm{SD} ; \mathrm{n}=34\end{array}$ & $\mathrm{p}$ \\
\hline SDNN, ms & $78.67 \pm 36.89$ & $75.77 \pm 26.02$ & $68.29 \pm 29.35$ & $\begin{array}{l}\mathrm{p}_{1}=0.914 \\
\mathrm{p}_{2}=0.271 \\
\mathrm{p}_{3}=0.318\end{array}$ \\
\hline RMSSD, ms & $79.89 \pm 45.70$ & $83.65 \pm 35.99$ & $76.06 \pm 41.07$ & $\begin{array}{l}\mathrm{p}_{1}=0.670 \\
\mathrm{p}_{2}=0.808 \\
\mathrm{p}_{3}=0.363\end{array}$ \\
\hline $\mathrm{TP}, \mathrm{ms}^{2}$ & $6567.20 \pm 5428.85$ & $5378.06 \pm 3928.33$ & $4725.18 \pm 3536.20$ & $\begin{array}{l}\mathrm{p}_{1}=0.490 \\
\mathrm{p}_{2}=0.208 \\
\mathrm{p}_{3}=0.486\end{array}$ \\
\hline VLF, $\mathrm{ms}^{2}$ & $2223.96 \pm 1848.89$ & $1425.25 \pm 1277.07$ & $1324.88 \pm 1033.10$ & $\begin{array}{l}\mathrm{p}_{1}=0.018 \\
\mathrm{p}_{2}=0.009 \\
\mathrm{p}_{3}=0.856\end{array}$ \\
\hline $\mathrm{LF}, \mathrm{ms}^{2}$ & $1796.39 \pm 1568.09$ & $1290.69 \pm 831.58$ & $1104.35 \pm 804.67$ & $\begin{array}{l}\mathrm{p}_{1}=0.435 \\
\mathrm{p}_{2}=0.077 \\
\mathrm{p}_{3}=0.262 \\
\end{array}$ \\
\hline $\mathrm{HF}, \mathrm{ms}^{2}$ & $2546.82 \pm 2534.75$ & $2662.31 \pm 2694.14$ & $2225.62 \pm 2334.92$ & $\begin{array}{l}\mathrm{p}_{1}=0.754 \\
\mathrm{p}_{2}=0.683 \\
\mathrm{p}_{3}=0.415\end{array}$ \\
\hline VLF,\% & $37.88 \pm 13.88$ & $29.71 \pm 14.41$ & $32.71 \pm 14.83$ & $\begin{array}{l}\mathrm{p}_{1}=0.013 \\
\mathrm{p}_{2}=0.100 \\
\mathrm{p}_{3}=0.289\end{array}$ \\
\hline $\mathrm{LF}, \%$ & $28.16 \pm 8.91$ & $27.59 \pm 10.72$ & $25.57 \pm 9.83$ & $\begin{array}{l}\mathrm{p}_{1}=0.512 \\
\mathrm{p}_{2}=0.168 \\
\mathrm{p}_{3}=0.494\end{array}$ \\
\hline $\mathrm{HF}, \%$ & $33.97 \pm 14.49$ & $42.71 \pm 17.22$ & $41.72 \pm 17.56$ & $\begin{array}{l}\mathrm{p}_{1}=0.031 \\
\mathrm{p}_{2}=0.062 \\
\mathrm{p}_{3}=0.895\end{array}$ \\
\hline $\mathrm{LF} / \mathrm{HF}$ & $1.08 \pm 0.73$ & $0.82 \pm 0.54$ & $0.95 \pm 0.93$ & $\begin{array}{l}\mathrm{p}_{1}=0.117 \\
\mathrm{p}_{2}=0.155 \\
\mathrm{p}_{3}=0.945\end{array}$ \\
\hline
\end{tabular}

Note: $\mathrm{p}_{1}$ - statistical significance of differences between indicators July - December; $\mathrm{P}_{2}$ - statistical significance of differences between the indicators July - February; $\mathrm{p}_{3}$ - statistical significance of differences between the indicators December - February. Mann-Whitney test.

By the middle of the competitive period at rest, very low-frequency waves (VLF waves) in absolute and relative units decrease. In December, there is a redistribution of the ratio of the spectrum waves:the contribution ofHF waves to the total regulation power increases from $34 \%$ to $43 \%$ compared to July (Table 2). The functioning of the sympathetic system throughout the study remains unchanged, which is confirmed by the power data of $\mathrm{LF}$ waves( $\left.\mathrm{LF}, \mathrm{ms}^{2} ; \%\right)$.

To the middle of the competitive period, at rest, the distribution of the contribution of various structures of autonomic regulation varies from $\mathrm{LF}<\mathrm{HF}<\mathrm{VLF}$ to $\mathrm{LF}<\mathrm{VLF}<\mathrm{HF}$. However, these changes do not affect the functional status of hockey players, determined by the integrative indicators of HRV (Gavrilova E.A., 2015), which remain unchanged throughout the observation period (Table 1).

When conducting an active orthostatic test, the reactivity of the parasympathetic nervous system in response to orthostasis was stable throughout the observation period. However, the level of adaptive reserves turned out to be reduced compared to literature data for elite hockey players (Mikhailov V.M.,2000; Mikhailov V.M.,Filkina O.M.,\&Shanina T.G., 2009). This fact is confirmed by the value of 30:15 (M $\pm \mathrm{m}$; SD) and its dynamics during the period of intense physical exertion - July: $1.30 \pm 0.03$; 0.23 ; December: $1.29 \pm 0.04 ; 0.23$; February: $1.31 \pm 0.04 ; 0.21 ; p>0.05$ in all cases. Establishing adaptive reserves only by the reactivity of the parasympathetic system without reactivity of the sympathetic system was due to the need to evaluate HRV parameters for 20-25 hockey players in a limited time, i.e. within 2-3 hours on the same day. Since HRV indicators can significantly change under the influence of physical activity in microcycles and mesocycles of sports training (Gavrilova E.A., 2015), failure to comply with these conditions would significantly complicate the interpretation of HRV data in general and could lead to incorrect judgments.

To solve the problem of assessing the impact of age factors and the specificity of physical activity on HRV indicators, a prospective cross-sectional study was conducted at the end of February-early March. The comparison group was formed from 16-year-old physical education students. Due to the features of the 


\section{ELENA SURINA-MARYSHEVA, VADIM ERLIKH, LYDMILA KRIVOKHIZHINA, KSENIA MARCHENKO, SALAVAT KANTYUKOV}

curriculum in a specialized college, the level of physical activity of students in the control group was considered high.

As a result of comparing HRV indicators in the two groups, it was revealed that specific physical exertion did not affect the overall heart rate regulation power at rest, since SDNN and TP did not show statistically significant differences (Table 2). The influence of the specifics of physical activity is reflected in the functional activity of the vasomotor center of the medulla oblongata, which is confirmed by a statistically significant lower value of $\mathrm{LF}\left(\mathrm{ms}^{2}\right), \mathrm{LF} \%$ and $\mathrm{LF} / \mathrm{HF}$ indicators in the group of hockey players compared to physically active peers (Table 2 ).

Table 2. Indicators of heart rate variability of hockey players and physically active students (time domain method). Data are means $( \pm \mathrm{SD})$

\begin{tabular}{|c|c|c|c|}
\hline \multirow{2}{*}{ Indicators } & \multicolumn{2}{|c|}{ Groups } & \multirow{2}{*}{$\mathrm{p}$} \\
\cline { 2 - 4 } & $\begin{array}{c}\text { Physically active students } \\
\text { M } \pm \text { SD }\end{array}$ & $\begin{array}{c}\text { Hockey players } \\
\text { M } \pm \text { SD }\end{array}$ & 0.770 \\
\hline SDNN, ms & $63.60 \pm 12.52$ & $68.29 \pm 29.35$ & 0.009 \\
\hline RMSSD, ms & $45.67 \pm 12.19$ & $76.06 \pm 41.07$ & 0.922 \\
\hline TP, $\mathrm{ms}^{2}$ & $4042.07 \pm 2035.01$ & $4725.18 \pm 3536.20$ & 0,888 \\
\hline VLF, $\mathrm{ms}^{2}$ & $1111.60 \pm 524.33$ & $1324.88 \pm 1033.10$ & 0.021 \\
\hline LF, $\mathrm{ms}^{2}$ & $1800.67 \pm 1574.02$ & $1104.35 \pm 804.67$ & 0.264 \\
\hline HF, $\mathrm{ms}^{2}$ & $1129.87 \pm 804.21$ & $2225.62 \pm 2334.92$ & 0.488 \\
\hline VLF, $\%$ & $30.59 \pm 15.75$ & $32.71 \pm 14.83$ & 0.001 \\
\hline LF, $\%$ & $42.35 \pm 18.32$ & $25.57 \pm 9.83$ & 0.005 \\
\hline HF, $\%$ & $27.07 \pm 10.86$ & $41.72 \pm 17.56$ & 0.004 \\
\hline
\end{tabular}

Note: $\mathrm{p}$ is the statistical significance of differences. Mann-Whitney test

In hockey players, compared to physically active peers,in February, the activity of the parasympathetic system (RMSSD) was increased, which resulted in an increase in HF\% (Table 2). During this period of sports training, players have a different correlation of various mechanisms of vegetative regulation - high-frequency waves prevail in cardiorhythm: $\mathrm{HF}>\mathrm{VLF}<\mathrm{LF}$ - hockey players; $\mathrm{LF}>\mathrm{VLF}<\mathrm{HF}$ - students.

Compared to physically activestudents, hockey players have a significantly lower 30:15 (hockey players: $\mathrm{M} \pm$ $\mathrm{SD}=1.31 \pm 0.21$; physically activestudents: $\mathrm{M} \pm \mathrm{SD}=1.51 \pm 0.18 ; \mathrm{p}<0.001)$.

\section{Discussion}

In a state of relative physiological rest for hockey players, by the middle of the competitive period, a favorable matrix for heart rate regulation has been formed - the vagosympathetic interaction of the sympathetic and parasympathetic system is biased towards increasing vagal influence. An increase in autonomy in heart rate regulation occurs under the influence of specific physical activities, which should contribute to accelerating the recovery of energy and plastic resources. The age-specific feature of adolescents aged 15-16 years is the preservation of the influence of suprasegmental centers of autonomic regulation at rest, as evidenced by the number of very slow waves (VLF) in the total wave structure of the cardiac rhythmogram at a level of 30-32\%, regardless of the specificity of physical activity. According to the literature (Mamonova S.B., Saburtsev S.A., \&Krylov V.N., 2016).) At this age in adolescents not involved in sports, the share of influences from cerebralergotropic structures accounts for up to $42 \%$. By the middle of the competitive period, in hockey players aged 15-16 years, regulation activity from the higher subcortical centers of vegetative regulation decreases and then remains unchanged $(32 \%-33)$. Despite a decrease in the activity of central ergotropic influences (VLF) in hockey players, they continue to have a great influence on heart rate regulation at this age. This fact indirectly indicates emotional stress due to neuro-hormonal changes in the pubertal period.

Autonomization of the cardiovascular systemamong hockey players aged 15-16 years at relative physiological rest is accompanied by imperfection of heart rate regulation in response to functional loads. The literature draws attention to the spastic nature of the reactions of the vascular bed to dosed physical activity in hockey players (Shaikhelislamova M.V., Sitdikov F.G., Zefirov T.L., \&Dikopolskaya N.B., 2015): an insufficient decrease in the total peripheral vascular resistance was revealed. This led to increased average hemodynamic pressure and increased functional load on the transport network of the cardiovascular system. The hyperreactivity of the sympathetic system to functional loads, apparently, contributes to an antagonistic decrease in the reactivity of the parasympathetic system to the orthostasic test. The influence of specialized physical loads is indirectly confirmed by reduced 30:15 compared to physically active students, which reflects the reactivity of the parasympathetic system and the level of adaptive reserves. The value of 30: 15 in hockey players is close to the value of 30: 15 in teenagers who are not involved in sports (Mikhailov V.M., 2000; Mikhailov V.M.,Filkina O.M.\&Shanina T.G., 2009). Earlier, we noted that, despite the gradual increase with age, 30:15 in hockey 


\section{ELENA SURINA-MARYSHEVA, VADIM ERLIKH, LYDMILA KRIVOKHIZHINA, KSENIA MARCHENKO, SALAVAT KANTYUKOV}

playersby 15 - 16 years, was on the lower boundary of the reference limits (1.25-1.75, cited by Gavrilova E.A., 2015). Moreover, among hockey players of the national team of Russia U-16, 30: 15 tends to the upper limit of the norm for adult athletes (Mikhailov V.M. Filkina O.M.,\&Shanina T.G., 2009). According to Pokhachevsky A.A. et al. (Pokhachevsky A.L., Mikhailov V.M., Gruzdev A.A., Petrovitsky A.A., Sadkov A.V., Kolesov N.V., Fomichev A.V., Ssorin S.S., Glushkov S.A., \&Khanykova S.V., 2006) in the future, in adults who are not involved in sports, the reactivity of the parasympathetic systemremains unchanged. Rational motor activity increases the reactivity of the parasympathetic system. Changes in the reactivity of the sympathetic and parasympathetic system may be connected with irrational hypoxic loads. It is known that the periodic effect of normobaric hypoxia of "normal" intensity and duration has a cardio- and angioprotective effect due to activation of antioxidant protection, increased cellular energy production, increased microvascular network density in skeletal muscle, myocardium and brain (Manukhina E.B., Belkina L.M., Lyamina N.P., Budanova O.P., Smirin B.V., Mallet R.T., Downey G.F., 2015). If the duration and intensity of the hypoxic loads does not matchthe hockey player's body, the positive effects should be replaced by negative ones due to inhibition of tissue respiration processes, damage to cellular structures and reduced energy production, including in the regulatory structures of the body.

\section{Conclusions}

In the competitive period,in hockey players agedfrom 15 to 16 years, the influence of the vagus centers on heart rate increases. At the same time, the activity of the higher subcortical centersremains unchanged and corresponds to age. The increased influence of higher subcortical structures of the autonomic system on heart rate regulation indirectly indicates the emotional stress of hockey players. Unlike the resting state, heart rate regulation in response to orthostasis has not yet been formed, which may be the result of exposure to irrational physical activity, including those of hypoxic orientation.

\section{Acknowledgment}

This article was supported by Act No 211 dd. March 16, 2013 (Government of the Russian Federation), Contract No 02. A03.21.0011. The studies were carried out as part of the state assignment (Grant No 19.9731.2017 / БЧ, Ministry of Education and Science of the Russian Federation).

\section{References}

Pal'ov, R., Pivovarniček, P., Jančoková, L. (2017) Comparison of the current level of the selected speed abilities of juniors in terms of player positions in ice hockey. Journal of Physical Education and Sport, Vol 17 Sup. 1, Art 19, pp.122 - 126 .

Jayanthi N., Pinkham C., Dugas L., Patrick B., \&Labella C. (2013). Sport specialization in young athletes: evidence-based recommendations Sports Health. 5(3), pp. 251-257.

Iordanskaya F.A. (2010) Features of the adaptation of the cardiovascular system of young athletes to the loads in modern ice hockey. Bulletin of Sports Science. 3, pp. 33-38.

ShaikhelislamovaM.V., SitdikovF.G., DikopolskayaN.P, BilalovaG.A., \&KayumovaG.M. (2009). Age- and sexrelated characteristics and mechanisms of adaptations during the prepubertal and pubertal periods of development. Human physiology. 35(6), pp. 103-110.

Baevsky, R. M., \& Ivanov, G. G. (2001). Cardiac Rhythm Variability: The Theoretical Aspects and Opportunities of Clinical Application (Lecture). Ultrasound and Functional Diagnostics. 3. pp. 108-207.

ChuyanE.N.,BiryukovaE.A., \&RavaevaM.Yu. (2008). Physiological mechanisms of heart rate variability (literature review). Scientific notes of the Vernadsky Crimean Federal University. Biology. Chemistry. 21 (60) (3). pp. 168-189.

Tonello, L., Rodrigues, F.B., \& Souza, J.W. (2014). The role of physical activity and heart rate variability for the control of work related stress. Front Physiol, 5(67), https://doi.org/10.3389/fphys.2014.00067

Sivokhov V.L., Sivokhova E.L., \&Mirolevich D.V. (2010). Modern biomedical support engaged in physical culture and sport. Irkutsk : Center for biomedical research Irkutsk state technical University.

Leti, T, \&Bricout, V.A. (2013). Interest of analyses of heart rate variability in the prevention of fatigue states in senior runners. AutonNeurosc, 1-2(173), pp. 14-21.

Kudrya, O.N. (2009). Heart rate variability indicators in athletes with different specifics of the training process. Sports medicine, 63 (3), pp. 20-26.

Karpenko, Yu..D. (2010). Age-related peculiarities of heart-rate variability in schoolchildren depending on their study load. Bulletin of ChGPU named after IYa Yakovlev., 68(4), pp. 80-85

Danieli A., Lusa L., Potočnik N., Meglic B., Grad A., \&Bajrovic F.F. (2014). Resting heart rate variability and heart rate recovery after submaximal exercise. ClinAutonRes.. 24(2). pp.53-61. 
Seifert G., Calaminus G., Wiener A., \&Cysar D. (2014) Heart ratevariability reflects the natural history of physiological development in healthy children and is not associated with quality of life. PLoS One. 9(3). e91036. doi: 10.1371/journal.pone.0091036

Shlyk, N.I. (2009). Heart rate and type of regulation in children, adolescents and athletes. Izhevsk: Publishing house "Udmurtia University".

Mikhaylov, V.M. (2000). Heart rate variability. Practical experience. Ivanovo: Publishing house of the Ivanovo state medical Academy.

Ban', A.S., \&Zagorodnyi, G.M. (2010). Possible errors in the analysis of heart rate variability. Problems of health and ecology, (3), pp. 119-123.

Gavrilova, E.A. (2015). Sports, stress, heart rate variability. Moscow: Sports.

Schmitt L., Regnard J., Desmarets M., Mauny F., Mourot L., Fouillot J.P., Coulmy N., \& Millet G. (2013) Fatigue shifts and scatters heart rate variability in elite endurance athletes. PLoS One, 8(8). e71588. doi: 10.1371 / journal.pone.0071588.

Heart rate variability. Standards of measurement, physiological interpretation, and clinical use. Task Force of The European Society of Cardiology and The North American Society of Pacing and Electrophysiology (Membership of the Task Force listed in the Appendix). (1996). European Heart Journal, 17, pp. 354-381.

Gisselman A.S., D’Amico M.S., James M. (2017).Optimizing inter-session reliability of heart rate variability the effects of artefact correction and breathing type.Journal Strength Cond Res. October 10, - Volume Publish Ahead of Print - Issue - pdoi: 10.1519/JSC.0000000000002258

Kowalewski M.A., \& Urban M. (2004). Short- and long-term reproducibility of autonomic measures in supine and standing positions ClinSci (Lond). 106 (1), pp. 61-66.

MikhailovV.M., FilkinaO.M., Shanina T.G. (2009). Heart Rate Variability Physiological Norm Parameters Limits in Healthy Teenagers in Dependence of Sex and Training Level. Ultrasound and functional diagnostics. 3. pp. 67-73.

Mamonova, S.B., Saburtsev, S.A., \&Krylov, V.N. (2016). Heart rate variability in schoolchildren with deforming diseases of the bone-muscular system. Journal of medical and biological research. 1, pp. 51-62.

Shayhelislamova, M.V., Sitdikov, F.G., Zefirov, T.L., \&Dikopolskaya, N.B. (2015). Hemodynamic status of prepubertal and pubertal hockey players. Human Physiology, 41 (4), pp. 420-427.

Pokhachevsky A.L., Mikhailov V.M., Gruzdev A.A., Petrovitsky A.A., Sadkov A.V., Kolesov N.V., Fomichev A.V., Ssorin S.S., Glushkov S .A., \&Khanykova S.V. (2006). Functional status and adaptive reserves of the body. Bulletin of Novgorod State University. 35. pp. 11-15.

Manukhina E.B., Belkina L.M., Lyamina N.P., Budanova O.P., Smirin B.V., Mallet R.T., Downey G.F. (2015). Cardioprotective effect of adaptation to hypoxia and its mechanisms: Experimental and clinical studies. CardioSomatics. S1. pp. 64. 